\title{
A Review on Litter Decomposition by Soil Fungal Community
}

\author{
P.A Geethanjali ${ }^{1}$ and Prof.M. Jayashankar ${ }^{2}$ \\ ${ }^{1}$ Department of Microbiology, Field Marshal K M Cariappa College, Madikeri, Kodagu (D), \\ Karnataka, India.) \\ ${ }^{2}$ DOS and Research in Microbiology, PG Centre, Chikka Aluvara, Somwarpet, Kodagu(D), Karnataka, India.)
}

\begin{abstract}
Fungi play an important role in plant litter decomposition in forest ecosystems through nutrient recycling and humus formation in soil because they attack the lingo-cellulose matrix in litter that other organisms are unable to assimilate. Fungi are considered to be the key players in litter decomposition because of their ability to produce a wide range of extracellular enzymes, which allows them to efficiently attack the recalcitrant ligno-cellulose matrix that other organisms are unable to decompose. Biochemical decomposition of leaf litter is a sequential process that initially involves the loss of the less recalcitrant components followed by the degradation of the remaining highly recalcitrant compounds. Litter quality changes during the course of its transformation and so does the activity of litter-associated microorganisms especially fungi. These changes are accompanied by a succession of microbial litter decomposers that reflect the varied catabolic capabilities that are sequentially required to complete the process of litter decomposition. The review reveals that fungi are divided into three functional groups according to their substrate utilization patterns during litter decomposition: lingo-cellulose decomposers that attack both lignin and cellulose in various proportions, cellulose decomposers that preferentially attack carbohydrates and sugar fungi that rely on soluble sugar for growth. Plant organic matter transformation leads to the disappearance of easily utilizable compounds and to the formation of recalcitrant ones. As a consequence, the chemical and spatial heterogeneity of the substrate changes with time. This process results in the formation of novel niches and a potential increase in fungal diversity.
\end{abstract}

Keywords: Litter, Decomposition, Successional Changes, Fungi, Enzymes

\section{Introduction}

The litter plays an important role in forest ecosystems. Decomposition of mixed leaf litters has recently become an active research area. In this paper successional changes brought about by litter harboring fungi and decomposition mechanisms concluded by researchers is summarized. Plant litter represents a major source of organic carbon in forest soils. Its decomposition is a complex process that involves mineralisation and transformation of organic matter. Decomposition of plant litter is a key step in nutrient recycling. As most of the plant biomass-derived carbon in the forests is mineralised in the litter layer, an understanding of this process and the microorganisms involved is essential for the identification of factors that affect global carbon fluxes. Litter is dead plant material, such as leaves, bark, needles and twigs, that has fallen to the ground. This dead organic material and its constituent nutrients are added to the top layer of soil, commonly known as the litter layer. Litter is the most abundant renewable carbon source on earth. It is mainly composed of cellulose, hemi cellulose, pectins, lignin and proteins [1]. Litter decomposition, a key ecosystem process that provides energy for microbial growth, releases nutrients for plant growth, influences ecosystem carbon storage, and thus may have a long-term effect on the climate. Litter decomposition is driven by a vast diversity of organisms that are structured in complex food webs. The biochemical decomposition of leaf litter is a sequential process that initially involves the loss of the less recalcitrant components (for example, oligosaccharides, organic acids, hemi-cellulose and cellulose followed by the degradation of the remaining highly recalcitrant compounds like lignin [2]. Litter quality changes during the course of its transformation and so does the activity of litterassociated microorganisms. These changes are accompanied by a succession of microbial litter decomposers. As a consequence of sequential plant organic matter transformation, the chemical and spatial heterogeneity of the substrate changes with time. This process can result in the formation of novel niches and a potential increase in fungal diversity or to the creation of more uniform environment with a potential decrease in diversity [3].

\section{Role Of Fungi In Litter Decomposition}

Fungi join bacteria as the primary decomposers in different ecosystems. They feed on the organic remains of dead plants. Because of their ability to produce a wide range of extracellular enzymes, fungi are considered to be the key players in litter decomposition. These enzymes have wide application in Pharmaceutical industry, agriculture, medicine, food industry, textiles, bioremediation, natural cycling, and many other ways. Fungal biotechnology has become an integral part of the human welfare [4]. 
The studies indicate that some fungi associated with living tree leaves are also found in association with decomposing leaf litter. The ability of live leaf-associated fungi to produce extracellular enzymes have led to the hypothesis that certain taxa may change from endophytism to a saprotrophic strategy. The molecular evidence indicates that fungi cultured from live leaves and decaying litter may indeed belong to the same taxa. The majority of fungi belong to the Ascomycota (71\%), Basidiomycota $(26 \%)$ and Glomeromycota $(1.8 \%)$ phylum [5]. Dominance of ascomycetous fungi in the early stages of litter decomposition was also been demonstrated [6]. Most efficient litter degraders are saprotrophic Ascomycetes and Basidiomycetes. Traditionally, these fungi are classified as brown rot (Ascomycota and Basidiomycota), white rot (Basidiomycota) and soft rot (Ascomycota) based on the appearance of the decaying material. Ligno-cellulose decomposers belonging to Basidiomycetes namely, Trametes versicolor, Collybia dryophila, $C$. peronata, Cyathus striatus, Clitocybe gibba, Micromphale sp. and Mycena polygramma, were found to be efficient decomposers of larch litter that attacked both lignin and carbohydrates [7].

Brown rot fungi preferentially attack cellulose and hemi-cellulose. Brown-rot fungi selectively degrade the cellulose and hemi-cellulose in litter, leaving behind the more recalcitrant lignin. The decayed wood is brown in colour and tends to form cubical cracks due to the brittle nature of the remaining lignin. Brown rot residues make up 'humus' in temperate forest soils and are important for mycorrhizal formation, moisture retention, and for sequestering carbon. Brown rot residues are highly resistant to decomposition and can remain in the soil for up to 300 years. Brown-rot fungi of importance include Serpula lacrymans, Fibroporia vaillantii, Coniophora puteana, Fomitopsis pinicola, Schizophyllum commune, Fomes fomentarius etc. [8].

White rot fungi are more common than brown rot fungi. These fungi degrade cellulose, hemi-cellulose, and lignin at approximately equal rates. The decayed wood is pale in colour, light in weight, and has a stringy texture. White rot fungi are the only organisms that can completely degrade lignin. Examples: Ganoderma lucidum, Phanerochaete chrysosporium, Armillariella mellea, Hypholoma fasciculare and Flammulina velutipes [9]. Soft-rot fungi secrete cellulase from their hyphae, an enzyme that breaks down cellulose in the wood. Examples of soft-rot-causing fungi are Chaetomium, Ceratocystis, Kretzschmaria deusta, Lulworthia, Halosphaeria and Pleosporain.

\section{Factors Affecting Litter Decomposition}

The proportion of litter decomposed by Basidiomycetes or Ascomycetes may vary among forest stands, depending on the biodiversity of fungal community within the forests. It has also been reported that lignin or nutrient $(\mathrm{N}$ or $\mathrm{P})$ contents, the $\mathrm{C}: \mathrm{N}$ ratio, and more recently the lignin : $\mathrm{N}$ ratio is a better predictor of litter decomposition rate [10].The main factors which control the litter decomposition are climate, litter quality ,the nature and abundance of the decomposing organisms. The lack of macronutrients, such as $\mathrm{N}, \mathrm{P}$, and $\mathrm{S}$ in fresh litter may limit the decomposition rates and the rates may be positively related to the concentration of $\mathrm{N}$. As the celluloses concentration disappear, the more recalcitrant compound, lignin, increases. In partly decomposed litter, decomposition rate of the whole piece of litter is determined by the degradation rate of lignin. At this stage, high $\mathrm{N}$ content will have a rate-retarding effect on lignin degradation and thus on the litter [11].

\section{Extracellular Enzyme Activity During Litter Decomposition}

Fungi produce a mixture of oxidative and hydrolytic enzymes to efficiently break down complex litter [12]. In plant cell walls, cellulose and hemi-cellulose is embedded in a pectin scaffold that requires pectin degrading enzymes, such as polygalacturonases and pectin lyases to weaken the plant cell wall and uncover hemi-cellulose and cellulose to further enzymatic degradation. Degradation of lignin is catalyzed by enzymes that oxidise aromatic compounds, such as phenol oxidases, peroxidises and laccases. Many fungi have multiple genes encoding lignin-degrading exo-enzymes [13]. To degrade cellulose, Basidiomycetes employ hydrolytic enzymes, such as endoglucnases, cellobiohydrolase and $\beta$-glucosidase [14].

\section{Conclusion}

Fungi play a significant role in decomposition of litter after their fall. They grow on the litter using easily accessible compounds. The review on successional changes brought about by fungi in litter reveals that Ascomycota dominates the fungal decomposer community with respect to abundance and activity especially in early stages of litter decomposition. It is followed by the Basidiomycota community. This suggests that the active part of microbial community changes over time. The fungal polymer-degrading enzymes can be detected at all times in the decomposing sites indicating that fungi are the main players in litter decomposition. The fungi from litter can be exploited for enzyme productions which are increasingly replacing conventional chemical catalyst. The versatility of litter decomposing fungi has been directed for a variety of newer industrial applications and fungal enzymes are ones which are finding increased industrial application. Among the enzymes amylase, cellulase, pectinase, $\alpha$-galactosidase, ligninase and invertase can be commercially produced by solid substrate fermentation process using agricultural materials. 
The role of litter decomposition in the global carbon cycle has increased recently for the reasons that it is an instrumental factor in ecological productivity, nutrient cycling and soil fertility. Biochemical decomposition of litter is a sequential process that initially involves the loss of the less recalcitrant components followed by the degradation of the remaining highly recalcitrant compounds Fungi are the key decomposers of litter in different ecosystems because of their ability to produce a wide range of extracellular enzymes. Studies indicate that the dominant litter degrading fungi belong to species of Basidiomycetes and Ascomycetes. Basidiomycetes were found to cause loss of lignin and carbohydrates in variable proportions, while Ascomycetes exclusively attack carbohydrates without delignification

\section{Acknowledgements}

The author is very grateful to Field Marshal K.M.Cariappa College, Madikeri, Mangalore University for providing necessary facilities, University Grants Commission, South Western Regional Office, Bangalore for the grants under MRP/12th plan and to everyone who have given their support.

\section{References}

[1] Dev, M. S. L., \& Thankamani, V. (2012). Biological characterization of a fast growing non-sporing alkalophilic lignin degrading fungus MVI.2011. Research in Biotechnology, 3(2), 62-77.

[2] Voriskova, J., \& Baldrian, P. (2013). Fungal community on decomposing leaf litter undergoes rapid successional changes. The ISME Journal, (7), 477-486

[3] Dickie, I.A., Fukami, T., Wilkie, J.P., Allen, R.B., \& Buchanan, P.K. (2012). Do assembly history effects attenuate from species to ecosystem properties? A field test with wood-inhabiting fungi. Ecol Lett .15, 133-141.

[4] Panda, T., Pani, P.K., \& Mohanty, M.N. (2010). A Comparative Account of the Diversity and Distribution of Fungi in Tropical Forest Soils and Sand Dunes of Orissa, India.J Biodiversity, 1 (1), 27-41.

[5] Voriskova,J., \& Baldrian, P. (2013). Fungal community on decomposing leaf litter undergoes rapid successional changes. The ISME Journal, (7), 477-486.

[6] Schneider, T., Keiblinger, K.M., Schmid, E., Sterflinger-Gleixner, K., Ellersdorfer, G., \& Roschitzki, B. (2012). who is who in litter decomposition? Metaproteomics reveals major microbial players and their biogeochemical functions. ISME J, 6, $1749-1762$.

[7] Osono1, T., Fukasawa, Y., \& Takeda, H. (2003). Roles of diverse fungi in larch needle-litter decomposition. Mycologia, 95 (5), $820-826$.

[8] Hammel, K.E., Kapich, A. N., Jensen, K.A., \& Ryan, Z. C. (2002). "Reactive oxygen species as agents of wood decay by fungi". Enzyme and Microbial Technology, 30 (4), 445-453.

[9] Boerjan, W., Ralph, J., \& Baucher, M.(2003). "Lignin biosynthesis". Ann. Rev. Plant Biol, 54 (1), $519-549$.

[10] Taylor, B.R., Parkinson, D., Parsons, W. F. J., \& Taylor. (1989). Nitrogen and Lignin Content as Predictors of Litter Decay Rates: A Microcosm Test. Ecology, 70, 97-104.

[11] Berg, B. \& Bodenokologie, L.F. (2000). Litter decomposition and organic matter turnover in northern forest soils. Forest Ecology and Management, 133 (1-2),13-22.

[12] Baldrian, P. (2009). "Microbial enzyme-catalyzed processes in soils and their analysis". Plant, Soil, and the Environment, 55, 370378.

[13] Stijn, L. Tim, B., \& Guido, V. (2009). "Plant cell walls: Protecting the barrier from degradation by microbial enzymes". Seminars in Cell \& Developmental Biology, 20 (9), 1064-1073.

[14] Valaskova, V., \& Baldrian, P. (2006). "Degradation of cellulose and hemicelluloses by the brown rot fungus Piptoporus betulinus production of extracellular enzymes and characterization of the major cellulases". Microbiology, 152 (12), 3613-3622. 